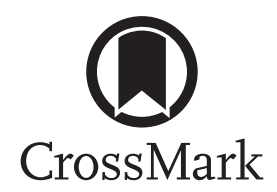

\title{
Forced expiratory flows' contribution to lung function interpretation in schoolchildren
}

\author{
Bernard Boutin ${ }^{1}$, Marc Koskas², Houda Guillo², Lucia Maingot ${ }^{2}$, \\ Marie-Claude La Rocca ${ }^{2}$, Michèle Boulé2 , Jocelyne Just ${ }^{1,3}$, Isabelle Momas ${ }^{4,5}$, \\ Alberti Corinne ${ }^{6}$ and Nicole Beydon ${ }^{2,7}$
}

\begin{abstract}
Affiliations: ${ }^{1}$ APHP, Allergology Dept, Centre de l'Asthme et des Allergies, Hôpital d'Enfants ArmandTrousseau, Paris, France. ${ }^{2}$ APHP, Unité Fonctionnelle de Physiologie-Explorations Fonctionnelles Respiratoires, Hôpital d'Enfants Armand-Trousseau, Paris, France. ${ }^{3}$ Sorbonne Universités, UPMC Univ Paris 06, UMR_S 1136, Institut Pierre Louis d'Epidémiologie et de Santé Publique, Equipe EPAR, F-75013, Paris, France. ${ }^{4}$ Université Paris Descartes, Sorbonne Paris Cité, EA 4064, Santé Publique et Environnement, Paris, France. ${ }^{5}$ Mairie de Paris, Direction de l'Action Sociale de l'Enfance et de la Santé, Cellule Cohorte, Paris, France. ${ }^{6} \mathrm{AP}-\mathrm{HP}$, Hôpital d'Enfants Robert Debré, Unité d'Epidémiologie Clinique and Inserm, CIE5, Paris, France. ${ }^{7}$ INSERM U93 Centre de Recherche Saint Antoine, Paris, France.
\end{abstract}

Correspondence: Nicole Beydon, Unité Fonctionnelle de Physiologie-Explorations Fonctionnelles Respiratoires (EFR), Hôpital Armand-Trousseau, 26 Avenue du Docteur Arnold Netter, 75571 Paris Cedex 12, France. E-mail, nicole.beydonatrs.aphp.fr

ABSTRACT Forced expiratory flow (FEF) at low lung volumes are supposed to be better at detecting lung-function impairment in asthmatic children than a forced volume. The aim of this study was to examine whether FEF results could modify the interpretation of baseline and post-bronchodilator spirometry in asthmatic schoolchildren in whom forced expiratory volumes are within the normal range.

Spirometry, with post-bronchodilator vital capacity within $10 \%$ of that of baseline in healthy and asthmatic children, was recorded prospectively. We defined abnormal baseline values expressed as z-scores $<-1.645$, forced expiratory volume in $1 \mathrm{~s}$ (FEV1) reversibility as a baseline increase $>12 \%$, FEF reversibility as an increase larger than the 2.5 th percentile of post-bronchodilator changes in healthy children.

Among 66 healthy and 50 asthmatic schoolchildren, only two (1.7\%) children with normal vital capacity and no airways obstruction had abnormal baseline forced expiratory flow at $25-75 \%$ of forced vital capacity (FEF25-75\%). After bronchodilation, among the 45 asthmatic children without FEV1 reversibility, 5 (11.1\%) had an FEF25-75\% increase that exceeded the reference interval.

Isolated abnormal baseline values or significant post-bronchodilator changes in FEF are rare situations in asthmatic schoolchildren with good spirometry quality.

@ERSpublications

Forced expiratory flows don't add useful information over forced expiratory volumes and their ratio in schoolchildren http://ow.ly/zo5MA

Received: April 022014 | Accepted after revision: July 042014 | First published online: Sept 032014

Support statement: The birth cohort is supported by the Paris Municipal Department of Social Action, Childhood, and Health (DASES)

Conflict of interest: Disclosures can be found alongside the online version of this article at erj.ersjournals.com

Copyright $\odot$ ERS 2015 


\section{Introduction}

It is recommended, in asthmatic subjects, to assess lung function impairment and lung function risk that should be minimised by the achievement of asthma control [1,2]. In asthmatic children, spirometry is routinely performed at baseline and after bronchodilator inhalation, in order to detect bronchial obstruction and significant bronchodilator response (i.e. reversibility). The post-bronchodilator (BD) increases in forced expiratory volume in $1 \mathrm{~s}(\mathrm{FEV} 1)$ and of its ratio to forced vital capacity (FVC) (i.e. FEV1/FVC) reflect airways bronchodilation, whereas the post-BD increase in FVC is mostly due to a decrease in air trapping, which is rarely present in children $[3,4]$ as opposed to adults with a severe asthma phenotype [5]. Post-BD changes in instantaneous flows at low lung volumes, i.e. forced expiratory flow at $50 \%, 75 \%$ or $25-75 \%$ of $\mathrm{FVC}$ (FEF50\%, $\mathrm{FEF} 75 \%, \mathrm{FEF} 25-75 \%$, respectively) cannot be used to state reversibility because 1) these measures have a large biological variability, 2) they can be influenced by the deep inspiration manoeuvre, and 3) they depend on the magnitude of the FVC itself [6]. However, the clinical relevance of FEF measurements could be more than anecdotal since early measures of maximal flow at functional residual capacity ( $V^{\prime}$ max,FRC at 2 months of age) better correlate to later FEV1/FVC and FEF25-75\% than to FVC or FEV1 measured in early adulthood [7]. Moreover, clinical implications for FEF have been claimed, such as optimising the diagnosis of bronchial hyperreactivity when used as a co-criterion to FEV1 decrease [8], or predicting significant bronchodilation [9]. Consequently, and despite recent considerations on the lack of clinical utility of baseline FEF to detect bronchial obstruction [10], physicians who routinely take care of asthmatic children are prone to scrutinise FEF, looking for baseline small-airways obstruction [11], or for significant FEF improvement (without FEV1 improvement) after asthma-controller treatment [12] or acute bronchodilation [13]. However, the relevant threshold to assess FEF reversibility has not been validated. The determination of this threshold must factor in the technical and biological variability of FEF as well as the baseline bronchial tone in healthy children [14].

In previous studies it was assumed that asthma mainly affected peripheral airways, which would be more readily reflected in an abnormal FEF than in FEV1 [12, 15-17]. However, the FEV1 varies with lung size and is, therefore, not a good index of airways obstruction, unlike the FEV1/FVC ratio. Using this latter index, a significantly impaired lung function was demonstrated in children with mild-to-moderate asthma as young as children aged 5 years [18].

We hypothesised that baseline spirometry and bronchodilator response (BDR) interpretation should not be substantially modified by FEF results in young asthmatic children with FEV1/FVC within the normal range and no FEV1 reversibility. Therefore, we recorded prospectively baseline spirometry and BDR in healthy and asthmatic children aged between 7 and 9 years and determined: 1) the number of children with baseline FEF outside the normal range despite normal FEV1/FVC and FVC; 2) the mean and the reference interval (95\% of healthy population) of spirometry indices changes after bronchodilation in healthy children; and 3) the proportion of asthmatic children with post-BD increase in FEF exceeding the reference interval while FEV1 was not reversible. Furthermore, we took advantage of the determination of BDR in healthy and asthmatic children to study different ways of assessing FEV1 reversibility (percentage of baseline, of predicted, limit of reference interval).

\section{Subjects and methods}

Children were recruited for this study from a general population-based cohort of healthy full-term newborns (Paris cohort, control group) [19] or were visiting for routine follow-up of asthma disease diagnosed according to international recommendations [2]. Children enrolled in the Paris cohort underwent lung function testing and blood sampling as part of the visit at 7 years of age, and we excluded children who had respiratory symptoms compatible with asthma [2] by using a standardised questionnaire and clinical examination. Family history and other personal medical condition and environmental exposures were recorded. The children's medical record was checked to report no asthma or wheezing after 3 years of age, and no more than two wheezing episodes without hospitalisation before 3 years of age. Asthmatic children aged between 7 and 9 years were included if born full-term and with no other diagnosis of chronic disease than asthma. Allergic status (skin-prick test and/or specific IgE), asthma control within the previous month [2] and current treatment were recorded. Short- and long-acting bronchodilators were withheld for at least $8 \mathrm{~h}$ and $12 \mathrm{~h}$, respectively, before the test. Children from both groups had to be free of acute respiratory infection for a minimum of 2 weeks. As multi-ethnic spirometry reference values were not available at the time of the study, only Caucasian children were included in both populations.

Technicians instructed the children to perform spirometry as recommended [20] in a seated position, nose-clip on, breathing through a mouthpiece and bacterial filter in a spirometer that was calibrated daily (BodyBox, Medisoft, Sorinnes, Belgium). At least three attempts were required and all tests were recorded to be reviewed and selected by two investigators according to recommendations [20]. After the baseline measurement, $200 \mu \mathrm{g}$ of salbutamol were delivered using a metered dose inhaler and a valve holding 
chamber (Vortex; Pari, Starnberg, Germany) and spirometry was performed $15 \mathrm{~min}$ later. The test was excluded from analysis if: 1) no acceptable flow-volume curve was available at baseline, or 2) post-BD (FVC) differed by $>10 \%$ from baseline. In the control group, exhaled nitric oxide (eNO) was measured according to recommendations using an electrochemical device (NIOX MINO; Aerocrine, Solna, Sweden) [21].

The birth cohort study was approved by the national ethics committee and parents gave their written informed consent. Our Institutional Review Board approved the project in asthmatic children who, together with their parents, gave informed consent for the study.

\section{Statistical analysis}

Spirometry indices were expressed as z-scores (number of standard deviations by which the measurement differs from the mean predicted value) using the prediction equations from the Global Lung Function Initiative (GLI-2012) for Caucasians [22].

We defined abnormal baseline values, expressed as z-scores, as smaller than -1.645 , FEV1 reversibility as an increase larger than $12 \%$ of the baseline value [6] (without the use of the $200 \mathrm{~mL}$ change criterion since, in these young children, forced volumes are nearly half those of adults), FEF reversibility baseline percentage as a post-BD change above the 2.5th percentile observed in healthy children. We also assessed FEV 1 reversibility in percentage of predicted value. Intra-measure coefficient of variations (CV) is the median of all individual intra-measure CVs, and inter-subject CV is the standard deviation/mean of raw values.

Quantitative variables are reported as median and interquartile range (IQR) or as mean \pm SD, and qualitative variables as number (per cent). Between-group comparisons were performed using the Chi-squared test for qualitative variables, and Wilcoxon or Student tests for not normally or normally distributed quantitative variables, respectively.

The relationships between baseline spirometry indices (z-scores) or BDR (percentage of baseline) and population characteristics were studied using a linear regression model. Correlations between quantitative variables were performed using Spearman's correlation test.

Receiver-operating characteristic (ROC) curves were generated, and compared as necessary, to assess diagnostic performance of FEF and FEV1 post-BD changes to distinguish between healthy and asthmatic children.

All tests were two-tailed. Statistical analyses were performed using SAS 9.3 software (SAS Inc, Cary, NC, USA).

\section{Results}

Between January 2011 and January 2012, 121 consecutive children from the Paris cohort study were included and used as the control (healthy) group in the study. 37 of which were excluded because of a previous diagnosis or a history highly suggestive of asthma, a further 16 did not achieve reliable baseline spirometry results, and another two children had an increase $>10 \%$ for FVC after bronchodilator administration. This left a total of 66 subjects in the control group. Between September 2011 and October 2012, 57 asthmatic children, aged between 7 and 9 years, were recruited into the study. Seven of which were excluded because of poor spirometry technique with unreliable results, this left a total of 50 children in the asthmatic group. The characteristics of the 66 healthy children and 50 asthmatic children are given in table 1. Asthmatic children were slightly older than the healthy children $(p<0.0001)$, but comparisons of spirometry indices were performed using z-scores and, therefore, took age into account. Allergic rhinitis and food allergy were more frequent in the asthmatic children, but eczema was equally present in both groups. Proven respiratory allergy was present in $68 \%$ of the asthmatic children, and an eNO $>25$ ppb was detected in $3.3 \%$ of the healthy children.

In healthy children there was no influence on baseline spirometry measurements of sex, family history of allergy or eczema, paternal asthma, current tobacco smoke exposure, eNO values, personal history of eczema, wheezing before the age of 3 years, or blood eosinophilia count. However, maternal asthma was related to lower FEV1/FVC $(p=0.01)$ and lower FEF25-75\% $(p=0.004)$. The above factors did not influence the BDR in healthy children, except sex, as FEF50\%increased more in young females than in young males $(\mathrm{p}=0.02) .33(66 \%)$ out of 50 asthmatic children used an asthma controller with a mean $\pm S D$ for beclomethasone-equivalent daily dose of $244 \pm 226 \mu \mathrm{g}$. During the previous month, asthma was controlled in $26(52 \%)$ children, partially controlled in 19 (38\%) children and not controlled in 5 (10\%) children in the asthma group.

Baseline spirometry intra-measure coefficients of variation were lower than the inter-subject coefficients of variation (table 2). Baseline FEV1, FEV1/FVC and $\mathrm{FEF}_{25}-75 \% \mathrm{z}$-scores were significantly lower in asthmatic children compared to healthy children $(\mathrm{p}<0.01)$, and were abnormal in only $6(5.2 \%), 6(5.2 \%)$ and $7(6 \%)$ 
TABLE 1 Characteristics of healthy and asthmatic study children

\begin{tabular}{|c|c|c|c|}
\hline & Healthy & Asthmatic & p-value \\
\hline Children n & 66 & 50 & \\
\hline Age years & $7.8(7.7-7.9)$ & $8.4(7.8-9.4)$ & $<0.0001$ \\
\hline Sex female/male $n$ & $26 / 40$ & $17 / 33$ & 0.55 \\
\hline Birth weight $\mathbf{g}$ & $3310(3060-3560)$ & 3300 (2970-3550) & 0.54 \\
\hline Birth weight z-score & $-0.07(-0.50-0.43)$ & $-0.19(-0.81-0.50)$ & 0.58 \\
\hline Maternal tobacco smoke during pregnancy & $9^{\#}(15)$ & $9(18)$ & 0.64 \\
\hline Current body mass index z-score & $0.02(-0.41-0.70)$ & $0.26(-0.36-1.39)$ & 0.14 \\
\hline Current caretakers tobacco smoke & $1^{\text {ๆ }}(27)$ & $22^{+}(45)$ & 0.06 \\
\hline Caretaker until 2 years of age & & & $<0.0001$ \\
\hline Family & 13 & 30 & \\
\hline Nanny & 21 & 9 & \\
\hline Nursery & 27 & 8 & \\
\hline Wheezing before 3 years of age & $25(38)$ & $35(70)$ & 0.001 \\
\hline \multicolumn{4}{|l|}{ Family history } \\
\hline Eczema and/or allergic rhinitis & $39(59)$ & NA & \\
\hline Asthma & 23 (35) & NA & \\
\hline \multicolumn{4}{|l|}{ Personal history } \\
\hline Eczema & $18(27)$ & $18^{\S}(38)$ & 0.25 \\
\hline Allergic rhinitis & $2(3)$ & $18(36)$ & $<0.0001$ \\
\hline Food allergy & 2 (3) & $12^{f}(26)$ & 0.0003 \\
\hline Respiratory allergy & NA & $32 / 47^{\# \#}(68)$ & \\
\hline Current exhaled nitric oxide ppb & $11(8.5-14.8)$ & NA & \\
\hline
\end{tabular}

Data are presented as median (interquartile range) or $n(\%)$ of the total population $(\mathrm{N})$, unless otherwise stated. NA: not available. ${ }^{\#}: \mathrm{N}=61 ;{ }^{\Uparrow}: \mathrm{N}=62 ;{ }^{+}: \mathrm{N}=49 ;{ }^{\S}: \mathrm{N}=48 ;{ }^{f}: \mathrm{N}=46 ;{ }^{\# \#}: \mathrm{N}=47$.

asthmatic children, respectively. Consistency between baseline impairments of FEV1 or FEV1/FVC and that of FEF $25-75 \%$ in all of the study children was as follows: three children (2.6\%) had abnormal FEF $25-75 \%$ with normal FEV1, and three children (of whom one belonged to the previous group and one had an abnormal FVC) had abnormal FEF25-75\% with a normal FEV1/FVC (fig. 1). Therefore, only two (1.7\%) children had an abnormal baseline FEF25-75\% with normal FEV1/FVC and FVC.

Post-BD changes in spirometry indices were not significantly different between healthy and asthmatic children (table 3$)$. Five asthmatic (10\%) and two healthy (3\%) children had FEV1 reversibility $(>12 \%$ baseline). The reference interval of spirometry changes in healthy children displayed an upper limit (2.5th percentile) of $11.2 \%, 41.3 \%, 50.5 \%$ and $59.9 \%$ for $\mathrm{FEV} 1, \mathrm{FEF} 25-75 \%, \mathrm{FEF} 50 \%$ and $\mathrm{FEF} 75 \%$, respectively (table 3). In seven children out of 104 without FEV1 reversibility, FEF changes exceeded this upper limit (FEF25-75\% n=7, FEF50\% $\mathrm{n}=5$, and FEF75\% $\mathrm{n}=5$ ). Among the 45 asthmatic children without FEV1 reversibility, the number of children with FEF changes exceeding the 2.5th percentile was 5 (11.1\%) for FEF25-75\% (fig. 2), 2 (4.4\%) for FEF50\% and 3 (6.7\%) for FEF75\%. There was no significant relationship between $\mathrm{FEF} 25-75 \%$ reversibility alone and health status (two out of 59 for healthy children and five out of 45 for asthmatic children, $\mathrm{p}=0.24$ ). Using an $11.2 \%$ baseline increase as the criterion for FEV1 reversibility (2.5th percentile in healthy children), 11 children had FEV1 reversibility ( $n=7$ asthmatic children and $n=4$ healthy children), and only three (6.7\%) asthmatic children had FEF25-75\% reversibility without FEV1 reversibility.

The median (IQR) post-BD change in FEV1 was 4.8 (2.6-6.3) \% of predicted with a 2.5 th percentile of $11.5 \%$. The post-BD changes in FEV1 expressed as percentage of baseline or of predicted were both correlated to baseline FEV1 \% predicted ( $r h o=0.33, p<0.001$ versus $r h o=0.23, p=0.01$, respectively), whereas post-BD FEV1 change expressed as percentage of baseline, but not as percentage of predicted, was correlated to the mean pre post-FEV1 \% predicted ( $\mathrm{rho}=0.19, \mathrm{p}=0.04$ versus $\mathrm{rho}=0.10, \mathrm{p}=0.33$, respectively).

ROC analysis showed the inability of post-BD percentage of baseline changes in FEF25-75\%, FEF50\% and FEF75\% to distinguish asthmatic from healthy children (area under the curve (AUC) was 0.46, 0.53 and 0.49 , respectively) in the study population. However, post-BD FEV1 change percentage of predicted had a higher AUC value than FEV1 change percentage of baseline ( 0.58 versus $0.44, \mathrm{p}=0.09$ ).

\section{Discussion}

We conducted a study in healthy and asthmatic schoolchildren to determine whether FEF interpretation could provide additional information to the lung function evaluation. We found that only 2 (1.7\%) of the 
TABLE 2 Baseline spirometry readings in the healthy and asthmatic children

\begin{tabular}{|c|c|c|c|c|c|c|c|}
\hline & \multicolumn{4}{|c|}{ Healthy children" } & \multicolumn{3}{|c|}{ Asthmatic children" } \\
\hline & Absolute values & z-scores & Intra-measure CV \% & Inter-subject CV \% & Absolute value & z-scores & Intra-measure CV \% \\
\hline FVC L & $1.84(1.69-2.04)$ & $0.37(-0.04-0.82)$ & $2.4(1.5-3.6)$ & 13 & $1.92(1.65-2.15)$ & $0.08(-0.37-0.76)$ & $2.0(1.3-2.7)$ \\
\hline FEV 1 L & $1.62(1.49-1.77)$ & $0.36(-0.08-0.96)$ & $1.9(1.4-3.2)$ & 11.8 & $1.57(1.43-1.80)$ & $-0.09(-1.01-0.66)^{* * *}$ & $2.1(1.4-2.9)$ \\
\hline FEV $1 / F V C$ & $0.88(0.85-0.91)$ & $-0.09(-0.56-0.39)$ & & & $0.85(0.79-0.90)$ & $-0.68(-1.27-0.24)^{* *}$ & \\
\hline PEF L.s ${ }^{-1}$ & $3.69(3.32-3.95)$ & NA & $4.2(2.8-6.3)$ & 12.7 & $3.70(3.14-4.26)$ & NA & $4.0(2.6-5.2)$ \\
\hline FEF $25-75 \% L \cdot s^{-1}$ & $2.08(1.87-2.37)$ & $0.33(-0.06-0.80)$ & $4.1(2.8-6.7)$ & 18.9 & $1.83(1.51-2.28)$ & $-0.21(-1.04-0.65)^{* * *}$ & $4.3(2.7-7.3)$ \\
\hline FEF50\% L.s ${ }^{-1}$ & $2.28(2.04-2.64)$ & NA & $3.8(2.6-6.6)$ & 21 & $1.97(1.69-2.50)$ & NA & $4.7(2.7-7.8)$ \\
\hline FEF $75 \% L \cdot S^{-1}$ & $1.08(0.92-1.24)$ & NA & $6.2(3.9-10.4)$ & 22.4 & $0.97(0.70-1.17)$ & NA & $8.5(4.7-11.5)$ \\
\hline
\end{tabular}

Data are presented as median (interquartile range), unless otherwise stated. FVC: forced vital capacity; FEV1: forced expiratory volume in 1 s; PEF: peak expiratory flow; FEF: forced expiratory flow at \% of FVC; CV: coefficient of variation (i.e. standard deviation/mean); NA: not available. " $\mathrm{n}=66$; ": $\mathrm{n}=50$. Asthmatic children at baseline were significantly different from healthy children. ${ }^{* *}: \mathrm{p}=0.01 ;{ }^{* * *}: \mathrm{p}=0.001$

TABLE 3 Bronchodilator response in healthy and asthmatic children

Post-bronchodilator healthy children ${ }^{\#}$

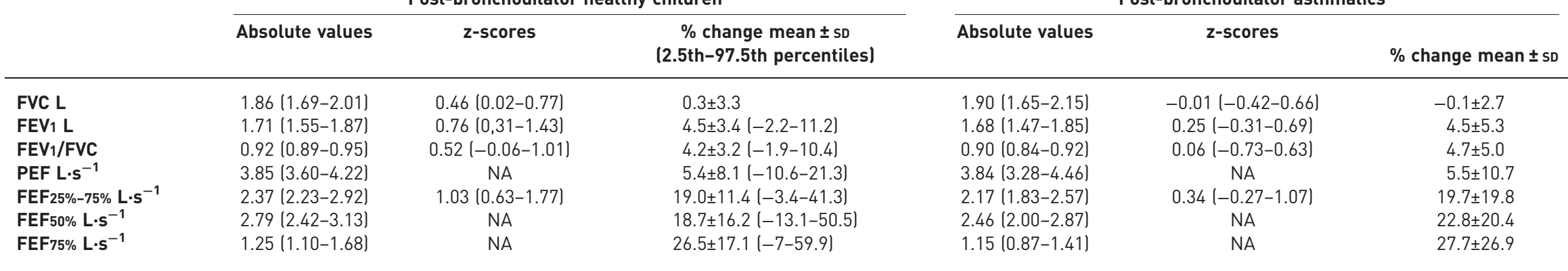

Results shown are median (interquartile range), unless otherwise specified. FVC: forced vital capacity; FEV1: forced expiratory volume in 1 s; PEF: peak expiratory flow; FEF: forced expiratory flow at $\%$ of FVC; NA: not available. ${ }^{\#}: n=61 ; \eta^{\natural}: n=50$ 


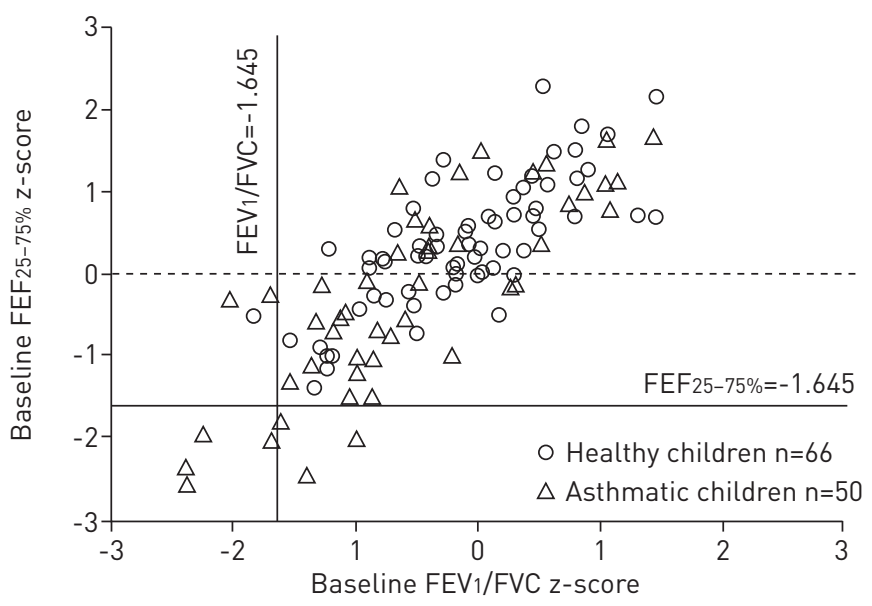

FIGURE 1 Baseline forced expiratory volume in $1 \mathrm{~s}$ (FEV1)/forced vital capacity (FVC) and forced expiratory flow at $25-75 \%$ of FVC (FEF25-75\%) expressed as z-scores in healthy and asthmatic children. Three asthmatics had a low FEF25-75\% with a normal FEV1/FVC, of whom one had a low FVC.

study children exhibited abnormal baseline FEF25-75\% despite having normal FEV1/FVC and FVC. We determined the reference interval of post-BD spirometry changes in healthy children, and found that among the 45 asthmatic children with no FEV1 reversibility, five (11.1\%) had a significant increase in FEF25-75\%; this prevalence rate was not significantly different from that in healthy children. ROC analysis showed that post-BD changes in FEF were of no help in distinguishing asthmatic from healthy children in the study population. In addition, our result suggested that, in schoolchildren, expressing the bronchodilator response in FEV1 as a percentage of predicted may be a better index than expressing it as a percentage of baseline.

The healthy children we studied were taking part in a birth-cohort survey aimed at describing early respiratory and allergic symptoms and their relationship to environmental exposure [19]. Thanks to the close follow-up of the children we are confident that we did not include asthmatic children in the control group, however we did not exclude children with environmental tobacco exposure, nor did we exclude children with one or two moderate wheezing episodes before three years of age. However, current environmental tobacco exposure and history of wheezing episodes before 3 years of age were less frequent

- Healthy children with FEV1 reversibility

O Healthy children without FEV1 reversibility

$\Delta$ Asthmatic children with FEV1 reversibility

$\triangle$ Asthmatic children without $F E V_{1}$ reversibility

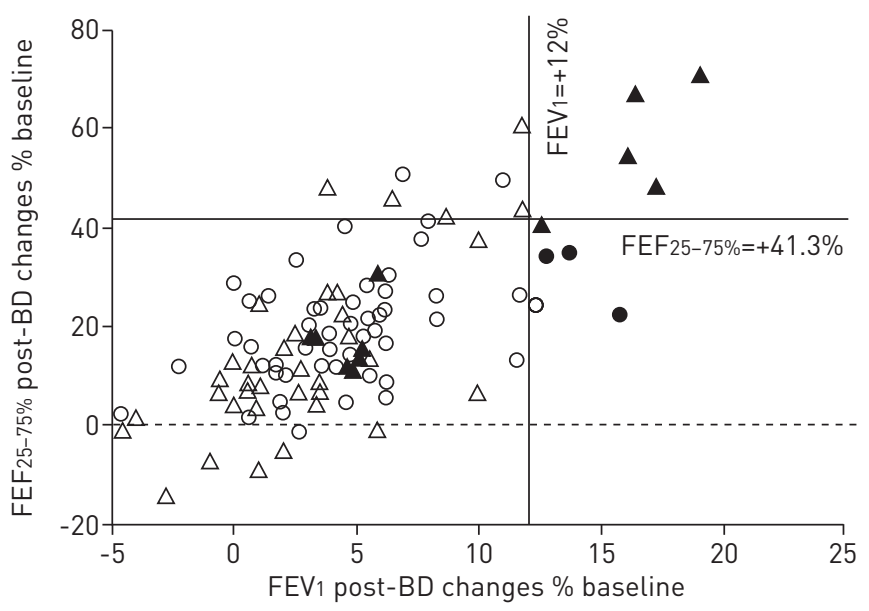

FIGURE 2 Post-bronchodilator (post-BD) changes consistency between forced expiratory volume in $1 \mathrm{~s}$ (FEV1) and forced expiratory flow at $25-75 \%$ of forced vital capacity (FEF25-75\%) changes expressed as percentage of baseline in 61 healthy children with and without FEV 1 reversibility and in 50 asthmatic children with and without FEV 1 reversibility. Discordant responses $n=5$ asthmatic children and $n=2$ healthy children. 
in the control group than in the asthmatic group, and were found to have no effect on baseline spirometry and on BDR.

We included children in a narrow age range because the inter-subject variability of FEF was found to vary highly with age [22]. In our single-centre study, conducted with experienced technicians working only with children, the intra-measure coefficients of variation of all the spirometry indices were very low (table 2) reflecting the good technical quality of the measurements. The FEF inter-subject coefficients of variation were higher than the intra-measure coefficients of variation, but remained within previously published values [22], in favour of true biological inter-subject variability. As to the potential effect of age on the BDR itself, in a study including two groups of children with significantly different ages (mean $\pm \mathrm{SD}$ ) $7.9 \pm 0.8$ versus $11.7 \pm 0.5$ years), the magnitude of $\mathrm{FEV} 1$ post-BD changes was similar (mean $\pm \mathrm{SD}$ ) $2.5 \pm 8.9$ versus $3.4 \pm 5.9 \%$ baseline) [23]. We feel that the small age difference between healthy and asthmatic subjects in this study is unlikely to have biased the BDR results.

As previously shown, the baseline lung function of the majority of asthmatic children was within the normal range [17]. Despite nearly half of the asthmatic children not having a controlled disease, only six (12\%) children had an abnormal baseline FEV1. Asthma control assessment includes an FEV1 measurement [2], which is unable to distinguish between groups of asthmatic children classified by symptom frequency and medication use [24]. However, there was the same proportion of children with an abnormal baseline FEV1/FVC $(n=6(12 \%))$ or an abnormal baseline FEF25-75\% $(n=7(14 \%))$. This shows that $\mathrm{FEF} 25-75 \%$ was not impaired more frequently than FEV1/FVC ratio in asthmatic children tested for routine follow-up. Moreover, the higher number of children with abnormal baseline FEF25-75\% than with abnormal baseline FEF50\% or FEF75\% is against the concept that instantaneous FEF at low volumes would better reflect a peripheral component of asthma than FEV1, because when FEV1/FVC is within the normal range (from 0.79 to 0.91 ), the FEV1 encompasses instantaneous FEF. The same result was found in 120 adults suspected of respiratory disease, in which $\mathrm{FEF} 25-75 \%$ was never found outside the limits of reference values when $\mathrm{FEV}_{1} / \mathrm{FVC}>0.75$ [25]. A recent large study confirmed this finding in children and in adults, with only $2.75 \%$ of subjects having an abnormal FEF25-75\% with FEV1/FVC and FVC within the normal range [10], which is close to $1.7 \%$ of the study children.

We found in the study that $3 \%$ of healthy and $10 \%$ of asthmatic children had FEV1 reversibility. The percentage of healthy children with FEV1 reversibility is in line with the expected proportion of normal subjects having a FEV1 increase $>2.5$ th percentile (i.e. $2.5 \%$ ). The frequency of reversibility in asthmatic children is not a constant finding and it has been shown that only $5 \%$ of children with mild or moderate asthma consistently exhibit a FEV1 increase $>12 \%$ after bronchodilator administration [26]. In our cross-sectional study, two thirds of the asthmatic children used regular inhaled corticosteroids, which may have increased the number of non-responders [26]. However, among the five asthmatic children with isolated FEF reversibility, four were using inhaled corticosteroids. Finally, since our aim was to sort out whether FEF post-BD changes were more sensitive than FEV1 to detect reversibility, it was more relevant to evaluate children with predominantly no FEV 1 reversibility.

We defined the reversibility as a post-BD change of more than mean $+1.96 \mathrm{sD}$ measured in healthy children. Using this definition, FEV1 reversibility (11.2\% baseline increase after $200 \mu \mathrm{g}$ of salbutamol) (table 3) fitted perfectly with the current recommendation in adults ( $12 \%$ baseline increase after $400 \mu \mathrm{g}$ of salbutamol) [6]. As there is no evidence that in young, healthy children a plateau in bronchodilator response has not been reached with $200 \mu \mathrm{g}$ salbutamol or equivalent drug [27], the $12 \%$ threshold seems to be acceptable in children. Dundas et al. [28] challenged the magnitude of this threshold in children aged from 5 to 10 years. The authors calculated a better sensitivity for a $9 \%$ over a $12 \%$ FEV1 increase threshold (50\% (95\% CI 38-62\%) versus 35\% (95\% CI 24-47\%), respectively), while specificity decreased but remained good (86\% (95\% 78-92\%) versus $98 \%$ (95\% CI 92-99\%), respectively). In our study, the use of a $9 \%$ threshold would have increased the number of responders and have decreased the number of children with only FEF reversibility, as would the use of an $11.2 \%$ threshold.

Expressing the bronchodilator response in FEV1 relative to the baseline value leads to the tendency of the most obstructed patients to spuriously display the largest bronchodilator response [29, 30]. Yet it is the current recommendation [6], the bias being partially overcome by requiring a minimal change of $200 \mathrm{~mL}$; the latter cannot be extended to children, in whom the change in FEV1 is age and height dependent [30]. Expressing bronchodilator responsiveness as percentage of predicted has been shown to be independent of baseline FEV 1 in asthmatic and non-asthmatic adults with airways obstruction $[29,31]$, or less correlated to baseline FEV1 than percentage of baseline change in children [30]. On the other hand the lower the $\mathrm{FEV} 1$, the larger the influence of regression to the mean when expressing the BDR as a percentage of the initial value. Therefore, WAALKENS et al. [30] studied the mean pre post-FEV1 and found, as we did, no significant correlation with BDR percentage of predicted. One drawback of BDR percentage of predicted 
was that it relied on the chosen reference dataset, which is no longer an issue thanks to the multi-ethnic, all-ages reference values equations [22]. In our study, percentage of predicted increases the ability of FEV1 to distinguish between healthy and asthmatic children, but more data in asthmatic children with different levels of airways obstruction and FEV1 reversibility are warranted to further evaluate and validate the use of percentage of predicted.

We checked for a stable FVC after bronchodilator administration, and the vast majority of children (96.4\%) achieved a $<6 \%$ baseline change in FVC, allowing for reliable comparisons between pre- and post-BD FEF values [32]. We found that the limits of significance for post-BD FEF changes were great (table 3). In a large study conducted in 492 healthy subjects aged 6-20 years, the reference intervals for FEF reversibility were narrower than ours (upper limit for FEF25-75\% 27.3\%, FEF50\% 27.4\%, and FEF75\% $42.8 \%)$, and FEV1 reversibility threshold (2.5th percentile of healthy children) was also slightly lower $(9.9 \%$ increase) [14]. Our study included younger children and no data are available on the possible change in FEF reversibility with age in healthy children. In healthy preschool aged children the mean+1.96sD BDR change in $\mathrm{FEF} 25-75 \%$ was $47.8 \%$, very close to our findings in healthy, young school children [13].

In our study, the use of a reasonable threshold to interpret FEF changes led to the detection of very few children with FEF reversibility alone, without any influence of health status. In a large population of asthmatic children aged 10-18 years, the authors used a $30 \%$ baseline increase (corresponding to one standard deviation from the mean without controlling for FVC changes) to define a meaningful post-BD increase in $\mathrm{FEF} 25-75 \%$, which increased by $53 \%$ the frequency of spirometry reversibility compared to the reversibility based on FEV1 changes [33]. However, the use of such a threshold in our healthy population would have led to diagnosing FEF reversibility in nine children (14.7\%, of whom only two had FEV1 reversibility), a higher prevalence than that of asthma in French schoolchildren [34].

Our study has some limitations. We did not administer placebo in order to assess the short-term biological and instrumental variability. In a study conducted in preschool aged children [13], healthy children had narrower limits of agreement in post-placebo changes than in post-BD changes (i.e. upper limits of $\mathrm{FEV}_{1}+14 \%$ versus $+18 \%$, and of $\mathrm{FEF} 25-75 \%+33 \%$ versus $+47.8 \%$, respectively). This result is in favour of spirometry changes due to bronchomotor tone exceeding that of mere biological and instrumental variability. The bronchomotor tone is nearly always present in healthy children [35], therefore in our study having only assessed BDR in healthy children, we have measured the maximal changes that could occur even though we are not able to separate the different components of this change.

Finally, we were not able to study the between-occasion reproducibility of the measurements in healthy children who came only once for a scheduled visit as part of a cohort survey. However, the low values of intra-measure coefficients of variation reflected the good technical skills of the participating healthy children who performed spirometry for the first time. We also paid attention to the absence of any recent acute respiratory tract infection that could have affected lung function on the day of the test.

In conclusion, we found that despite good intra-measure reproducibility, FEF have a larger inter-subject variability and post-BD variation than forced volumes. FEF rarely indicate baseline respiratory impairment that goes undetected with conventional spirometric indices, and are not superior to FEV1 in demonstrating a significant bronchodilator effect in schoolchildren. Finally, in the study population, post-BD FEF changes failed to distinguish healthy from asthmatic children. Therefore FEV1, FVC and FEV1/FVC remain the measurements of choice for asthma assessment and monitoring [1].

Repeated measures in different age groups of healthy children and inclusion of asthmatic children with different levels of bronchoreactivity are warranted to help solving the issue of the best way to express FEVıreversibility in school children.

\section{Acknowledgements}

We gratefully acknowledge help from Priscilla Boizeau (AP-HP, Hôpital d'Enfants Robert Debré, Unité d'Epidémiologie Clinique, Paris, France) with data management and statistical analysis.

\section{References}

1 US Department of Health and Human Services. National Heart Lung and Blood Institute. National Asthma Education and Prevention Program. Expert panel Report 3: Guidelines for the Diagnosis and Management of Asthma. Bethesda, NHLBI Health Information Center, 2007. Available from: www.nhlbi.nih.gov/guidelines/ asthma/asthgdln.pdf

2 Global Initiative for Asthma. Global Strategy for Asthma Management and Prevention. Updated 2012. www. ginasthma.org/local/uploads/files/GINA_Repor_March13_1.pdf Date last updated: December 2012.

3 Mahut B, Peiffer C, Bokov P, et al. Gas trapping is associated with severe exacerbation in asthmatic children. Respir Med 2010; 104: 1230-1233.

4 Mahut B, Peiffer C, Bokov P, et al. Use of specific airway resistance to assess bronchodilator response in children. Respirology 2011; 16: 666-671. 
5 Sorkness RL, Bleecker ER, Busse WW, et al. Lung function in adults with stable but severe asthma: air trapping and incomplete reversal of obstruction with bronchodilation. J Appl Physiol 2008; 104: 394-403.

6 Pellegrino R, Viegi G, Brusasco V, et al. Interpretative strategies for lung function tests. Eur Respir J 2005; 26: 948-968.

7 Stern DA, Morgan WJ, Wright AL, et al. Poor airway function in early infancy and lung function by age 22 years: a non-selective longitudinal cohort study. Lancet 2007; 370: 758-764.

8 Custovic A, Arifhodzic N, Robinson A, et al. Exercise testing revisited. The response to exercise in normal and atopic children. Chest 1994; 105: 1127-1132.

9 Simon MR, Chinchilli VM, Phillips BR, et al. Forced expiratory flow between $25 \%$ and $75 \%$ of vital capacity and FEV1/forced vital capacity ratio in relation to clinical and physiological parameters in asthmatic children with normal FEV1 values. J Allergy Clin Immunol 2010; 126: 527-534.

10 Quanjer PH, Weiner DJ, Pretto JJ, et al. Measurement of FEF $25-75 \%$ and FEF75\% does not contribute to clinical decision making. Eur Respir J 2014; 43: 1051-1058.

11 Ciprandi G, Capasso M, Tosca M, et al. A forced expiratory flow at $25-75 \%$ value $<65 \%$ of predicted should be considered abnormal: a real-world, cross-sectional study. Allergy Asthma Proc 2012; 33: e5-e8.

12 Patel AC, Van Natta ML, Tonascia J, et al. Effects of time, albuterol, and budesonide on the shape of the flow-volume loop in children with asthma. J Allergy Clin Immunol 2008; 122: 781-787.

13 Borrego LM, Stocks J, Almeida I, et al. Bronchodilator responsiveness using spirometry in healthy and asthmatic preschool children. Arch Dis Child 2013; 98: 112-117.

14 Casan P, Roca J, Sanchis J. Spirometric response to a bronchodilator. Reference values for healthy children and adolescents. Bull Eur Physiopathol Respir 1983; 19: 567-569.

15 McFadden ER Jr, Linden DA. A reduction in maximum mid-expiratory flow rate. A spirographic manifestation of small airway disease. Am J Med 1972; 52: 725-737.

16 Mostgaard G, Siersted HC, Hansen HS, et al. Reduced forced expiratory flow in schoolchildren with respiratory symptoms: the Odense Schoolchild Study. Respir Med 1997; 91: 443-448.

17 Long-term effects of budesonide or nedocromil in children with asthma. The Childhood Asthma Management Program Research Group. N Engl J Med 2000; 343: 1054-1063.

18 Strunk RC, Weiss ST, Yates KP, et al. Mild to moderate asthma affects lung growth in children and adolescents. $J$ Allergy Clin Immunol 2006; 118: 1040-1047.

19 Clarisse B, Nikasinovic L, Poinsard R, et al. The Paris prospective birth cohort study: which design and who participates? Eur J Epidemiol 2007; 22: 203-210.

20 Miller MR, Hankinson J, Brusasco V, et al. Standardisation of spirometry. Eur Respir J 2005; 26: 319-338.

21 ATS, ERS. Recommendations for standardized procedures for the online and offline measurement of exhaled lower respiratory nitric oxide and nasal nitric oxide, 2005. Am J Respir Crit Care Med 2005; 171: 912-930.

22 Quanjer PH, Stanojevic S, Cole TJ, et al. Multi-ethnic reference values for spirometry for the 3-95-yr age range: the global lung function 2012 equations. Eur Respir J 2012; 40: 1324-1343.

23 Tse SM, Gold DR, Sordillo JE, et al. Diagnostic accuracy of the bronchodilator response in children. J Allergy Clin Immunol 2013; 132: 554-559.

24 Bacharier LB, Strunk RC, Mauger D, et al. Classifying asthma severity in children: mismatch between symptoms, medication use, and lung function. Am J Respir Crit Care Med 2004; 170: 426-432.

25 Gelb AF, Williams AJ, Zamel N. Spirometry. FEV1 vs FEF25-75 percent. Chest 1983; 84: 473-474.

26 Sharma S, Litonjua AA, Tantisira KG, et al. Clinical predictors and outcomes of consistent bronchodilator response in the childhood asthma management program. J Allergy Clin Immunol 2008; 122: 921-928.

27 Dales RE, Spitzer WO, Tousignant P, et al. Clinical interpretation of airway response to a bronchodilator. Epidemiologic considerations. Am Rev Respir Dis 1988; 138: 317-320.

28 Dundas I, Chan EY, Bridge PD, et al. Diagnostic accuracy of bronchodilator responsiveness in wheezy children. Thorax 2005; 60: 13-16.

29 Weir DC, Sherwood BP. Measures of reversibility in response to bronchodilators in chronic airflow obstruction: relation to airway calibre. Thorax 1991; 46: 43-45.

30 Waalkens HJ, Merkus PJ, Van Essen-Zandvliet EE, et al. Assessment of bronchodilator response in children with asthma. Dutch CNSLD Study Group. Eur Respir J 1993; 6: 645-651.

31 Dompeling E, van Schayck CP, Molema J, et al. A comparison of six different ways of expressing the bronchodilating response in asthma and COPD; reproducibility and dependence of prebronchodilator FEV1. Eur Respir J 1992; 5: 975-981.

32 Sherter CB, Connolly JJ, Schilder DP. The significance of volume-adjusting the maximal midexpiratory flow in assessing the response to a bronchodilator drug. Chest 1978; 73: 568-571.

33 Rao DR, Gaffin JM, Baxi SN, et al. The utility of forced expiratory flow between $25 \%$ and $75 \%$ of vital capacity in predicting childhood asthma morbidity and severity. J Asthma 2012; 49: 586-592.

34 Delmas MC, Guignon N, Leynaert B, et al. Prevalence de l'asthme chez l'enfant en France [Prevalence of asthma among children in France]. Arch Pediatr 2009; 16: 1261-1269.

35 Riedel F, von der Hardt H. Variable response to inhaled salbutamol of different lung function parameters in healthy children. Lung 1986; 164: 333-338. 